\section{Commentary: More than 2 sides to the coin - the Goldilocks paradigm}

\author{
Stacey Chen, MD, and Eugene A. Grossi, MD
}

The mitral valve (MV) apparatus is a wonderfully complex anatomical structure, and any discordance in its components can result in mitral regurgitation (MR). Intrinsic alteration or pathology of this apparatus results in primary MR, whereas left ventricular dysfunction that compromises the function of the apparatus is known as secondary or functional MR. ${ }^{1}$ Improvements in surgical technique, operative experience, and advancements in multimodality cardiac imaging have contributed to excellent short- and long-term outcomes in the clinical management of these patients. ${ }^{2}$ In addition, there is an accelerating force, with specific minimally invasive and percutaneous transcatheter MV interventions being implemented in the larger overarching narrative of MR therapies.

In this issue of the Journal, Badhwar ${ }^{3}$ presents his expert opinion on the evolution of interventional transcatheter MV repair and replacement devices for the management of both primary and secondary MR. This review is particularly timely, as clinical trials for percutaneous investigational devices for MR are underway. ${ }^{4,5}$ Furthermore, the MitraClip (Abbott Vascular, Chicago, Ill), which was initially introduced in 2013 and indicated for use only in surgically prohibitive patients with primary MR, has most recently as of March 2019 been approved by the United States Food and Drug Administration for patients with secondary MR as well. With the growing number of investigational devices and the expanded indications for the MitraClip, the momentum for minimally invasive MV therapies is here, and it is imperative that MV surgeons are prepared with the appropriate knowledge base.

From the Department of Cardiothoracic Surgery, NYU Langone Health, New York, NY.

Disclosures: The authors reported no conflicts of interest.

The Journal policy requires editors and reviewers to disclose conflicts of interest and to decline handling or reviewing manuscripts for which they may have a conflict of interest. The editors and reviewers of this article have no conflicts of interest.

Received for publication April 20, 2020; accepted for publication April 21, 2020; available ahead of print May 1, 2020.

Address for reprints: Eugene A. Grossi, MD, Department of Cardiothoracic Surgery, NYU Langone Health, 530 First Ave, Suite 9V, New York, NY 10016 (E-mail: eugene.grossi@nyulangone.org).

J Thorac Cardiovasc Surg 2020;160:99-100 0022-5223/ $\$ 36.00$

Copyright (c) 2020 Published by Elsevier Inc. on behalf of The American Association for Thoracic Surgery

https://doi.org/10.1016/j.jtcvs.2020.04.090

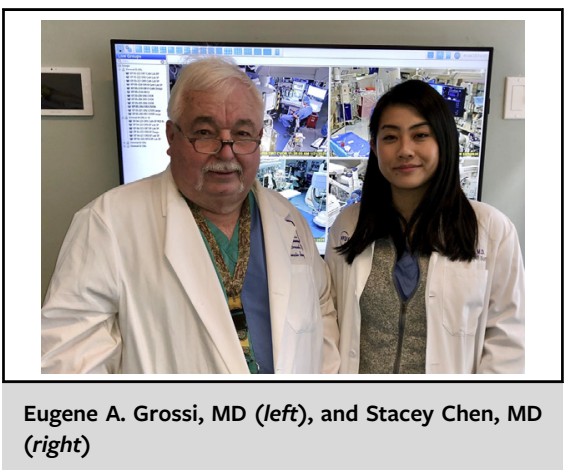

CENTRAL MESSAGE

As indications for mitral valve transcatheter devices expand, the mitral valve surgeon is tasked to evolve and master additional skillsets in the judicious management of mitral regurgitation.

Appropriate and optimal management of MR is predicated on a multidisciplinary heart team approach, and as Dr Badhwar advocates, this should be co-directed by a MV surgeon and interventional cardiologist. The expertise of the MV surgeon thus is paramount to the success of the future and soon-to-present landscape of MV treatment. Dr Badhwar specifically illuminates the concept of the "pursuit of equipoise," emphasizing that despite the incongruous results between the COAPT trial (Cardiovascular Outcomes Assessment of the MitraClip Percutaneous Therapy) and the MITRA-FR trial (Percutaneous Repair with the MitraClip Device for Severe Functional/Secondary Mitral Regurgitation), both studies clearly demonstrated that although some patients with secondary MR benefited from the MitraClip, others did not. ${ }^{6,7}$ This underlines the nuanced, judicious, and individualized evaluation of patients that must be performed by the multidisciplinary heart team, especially as the indications for transcatheter interventions are broadened to include surgical candidates.

We commend Dr Badhwar for his comprehensive review of the current and future directions of transcatheter MV therapies and perspective on the role of the MV specialist. With the evolution of MR treatment, so too must the MV surgeon evolve. As new modalities are introduced, the decision to choose which therapy is appropriate for which patient may prove even more challenging, as long-term outcomes are required to assess durability, functional outcomes, and survival. Like Goldilocks, ultimately, the "pursuit of equipoise" is the art of finding "just the right 
fit" for each patient. Although therapeutic modalities may evolve, the expectations called upon the MV specialist remain the same: proficiency, mastery, and equipoise.

\section{References}

1. Enriquez-Sarano M, Akins CW, Vahanian A. Mitral regurgitation. Lancet. 2009; 373:1382-94.

2. Zhou S, Egorova N, Moskowitz G, Giustino G, Ailawadi G, Acker MA, et al. Trends in MitraClip, mitral valve repair, and mitral valve replacement from 2000 to 2016. J Thorac Cardiovasc Surg. January 22, 2020 [Epub ahead of print].

3. Badhwar V. Transcatheter mitral valve intervention: consensus, quality, and equipoise. J Thorac Cardiovasc Surg. 2020;160:93-8.
4. Prendergast BD, Baumgartner H, Delgado V, Gerard O, Haude M, Himmelmann A, et al. Transcatheter heart valve interventions: where are we? Where are we going? Eur Heart J. 2019;40:422-40.

5. Weber A, Rucinskas K, Janusauskas V, Zakarkaite D, Zuber M, Vogel R, et al. Automated implantation of artificial mitral chords: preliminary results from the feasibility trial. Ann Thorac Surg. 2020;109:597-602.

6. Asch FM, Grayburn PA, Siegel RJ, Kar S, Lim DS, Zaroff JG, et al. Echocardiographic outcomes after transcatheter leaflet approximation in patients with secondary mitral regurgitation: the COAPT trial. J Am Coll Cardiol. 2019;74: 2969-79.

7. Obadia JF, Armoiry X, lung B, Lefevre T, Mewton N, Messika-Zeitoun D, et al. The MITRA-FR study: design and rationale of a randomized study of percutaneous mitral valve repair compared with optimal medical management alone for severe secondary mitral regurgitation. EuroIntervention. 2015;10:1135-60.
See Article page 93.

\section{Commentary: Mitral valve surgery in the new paradigm}

\author{
J. James Edelman, MBBS(Hons), PhD, ${ }^{\mathrm{a}}$ and \\ Vinod H. Thourani, MD ${ }^{\mathrm{b}}$
}

Badhwar ${ }^{1}$ provides a comprehensive review of contemporary transcatheter mitral valve (MV) therapy and its context within the various types of MV disease. With the emergence of new transcatheter MV technology there will soon be alternatives to the majority of traditional surgical treatments for MV disease. There are several points that are particularly important when considering the future of therapy for MV disease.

The multidisciplinary societies have suggested minimum volume requirements for the institution of transcatheter MV programs. Although these volume requirements are not a perfect proxy for quality, they are essential so that both new and traditional techniques will be offered in equipoise

From the ${ }^{\mathrm{a}}$ Department of Cardiothoracic Surgery, Fiona Stanley Hospital, Perth, Australia; and ${ }^{\mathrm{b}}$ Department of Cardiovascular Surgery, Marcus Valve Center, Piedmont Heart Institute, Atlanta, Ga.

Disclosures: Dr Thourani is an advisor/research for Abbott Vascular, Edwards Lifesciences, Boston Scientific, Medtronic, and Gore Vascular. Dr Edelman reported no conflicts of interest.

The Journal policy requires editors and reviewers to disclose conflicts of interest and to decline handling or reviewing manuscripts for which they may have a conflict of interest. The editors and reviewers of this article have no conflicts of interest.

Received for publication April 13, 2020; accepted for publication April 13, 2020; available ahead of print May 1, 2020.

Address for reprints: Vinod H. Thourani, MD, Department of Cardiovascular Surgery, Piedmont Heart Institute, 95 Collier Rd, Suite 5015, Atlanta, GA 30308 (E-mail: vinod.thourani@piedmont.org).

J Thorac Cardiovasc Surg 2020;160:100-1

$0022-5223 / \$ 36.00$

Copyright (c) 2020 by The American Association for Thoracic Surgery

https://doi.org/10.1016/j.jtcvs.2020.04.089
Check for updates

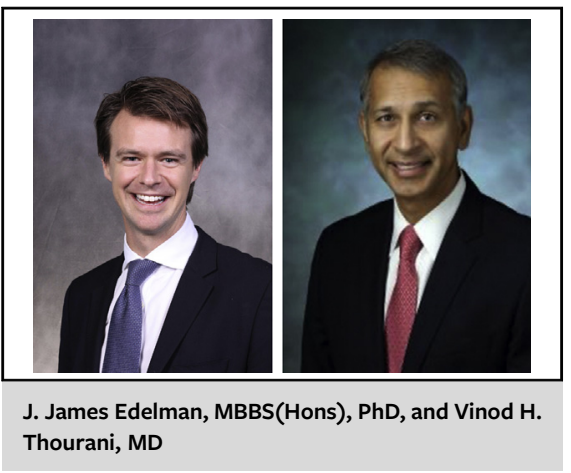

CENTRAL MESSAGE

Surgeons should embrace

emerging transcatheter mitral

valve technology. The emergence

of mitral valve specialists and

heart team collaboration will

improve transcatheter and sur-

gical results.

to the right patients. Mechanisms (such as a rapid access referral pathway to larger centers) must be in place for those hospitals that fall below the threshold volumes to ensure that appropriate patients have access to these innovative transcatheter therapies.

Within the past 5 years, a multitude of landmark trials have compared surgical, transcatheter, and medical therapy for those with moderate to severe functional mitral regurgitation. $^{2-5}$ These trials (eg, the National Heart, Lung, and Blood Institute Cardiothoracic Surgical Trials Network, the Cardiovascular Outcomes Assessment of the MitraClip Percutaneous Therapy for Heart Failure Patients With 